\title{
Information Literacy and Mathematics
}

\section{Education Students: A Case Study in Library Instruction}

\author{
M. H. Albro \\ Shippensburg University \\ K. Megan Sheffield \\ Clemson University \\ Anne Grant \\ Clemson University \\ Renna Tuten Redd \\ Clemson University
}

\begin{abstract}
Prior to 2016 library instruction for mathematics courses was nonexistent at Shippensburg University. The hiring of the STEM librarian in August 2016 led to an initiative to engage the mathematics faculty and students in using resources and services offered by the Ezra Lehman Memorial Library. This outreach resulted in two sessions of the Fundamentals of Mathematics course coming into the library for instruction in the fall semester. These first sessions found that detailed instruction in how to search and identify articles related to key concepts from the desired journal type was particularly useful to the students; however, these sessions also demonstrated a greater need for citation-focused instruction. Adapting the instruction session spring 2017 to include a more in-depth discussion about the necessity of citations showed a greater understanding of the concept by students in the course. Ultimately, this successful instruction improved the course instructor's perception of the student work and led to the scheduling of future library instruction sessions by other members of the mathematics department.
\end{abstract}

Keywords: information literacy for mathematics, mathematics education, library instruction, instruction, stem

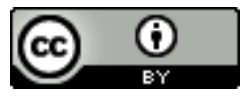

This is an Open Access article distributed under the terms of the Creative Commons Attribution 4.0 International License (http://creativecommons.org/licenses/by/4.0), which permits unrestricted use, distribution, and reproduction in any medium, provided the original work is properly cited. 


\section{Introduction and Literature Review}

The incorporation of information literacy concepts into STEM courses, courses that do not traditionally include either research elements or writing assignments, is a relatively new frontier for instruction librarians. There has been work to incorporate these concepts into some of the other STEM fields and in particular, information literacy modules have shown to be valuable to courses in the sciences (Storksdieck, 2016; Awasom, 2017; Scaramozzino, 2010). For example, one university has worked with a train-the-trainer model by introducing teaching assistants in charge of educating students in biology labs to incorporate information literacy concepts (Hartman, Newhouse, \& Perry, 2014). However, there is not a large amount of research when it comes to the integration of these modules into mathematics courses. Information literacy has proven to be well accepted in this subject as demonstrated in a study showing that found students were receptive to learning new ideas (Harris, 2017). Another study was described at a conference in 2012 and seeks to examine the information behavior of graduate students in math at different stages in their program (Li, 2012). A project at Fayetteville State University found that students were able to obtain necessary information literacy skills directly applicable to the course. (Jing, 2017). Yet another project in the field of engineering demonstrates the value of information literacy, not only as a teaching tool, but also as a means for outreach to faculty and students to raise awareness about the need for competence in information seeking behaviors (Stitz, 2010). The case study presented in the following article shows both the integration of information literacy concepts as well as the potential for library instruction outreach in the field of mathematics. 


\section{Context}

Shippensburg University is a public, state-system university in Shippensburg, Pennsylvania, which was established as the Cumberland Valley State Normal School by the Commonwealth of Pennsylvania in 1871. It is ranked among the top universities of the North by U.S. News \& World Report (2017). Shippensburg University matriculates approximately 6,000 undergraduate and 1,000 graduate students with a 20:1 student to faculty ratio (Shippensburg University, 2017).

Shippensburg University has one main library (Ezra Lehman Memorial Library) and one smaller library (Grace B. Luhrs Elementary School Library) located in the lab school on campus. Lehman Library consists of three floors of collections, study space, classroom space, and office space, while the Luhrs Library contains one floor with collections, a classroom, an office, and activity space. Within Lehman Library is the university archives and special collections, the academic success center, and the instructional technology office. Together, Lehman and Luhrs Libraries are referred to as "the library" on campus. Students most often frequent the Lehman Library, which is also where undergraduate and graduate library instruction typically occurs.

The library employs seven faculty, twelve staff, and a small number of student workers. Media services and information technology are organized within the same division as the library, and all three groups share one dean. Additionally, a dean and manager of library services serve the library, with human resources and other support services being provided through the university administration.

Information literacy classes and bibliographic instruction at Shippensburg University are taught by the faculty librarians at Lehman Library, who liaise with their assigned departments to develop opportunities for instruction and who share the task of providing library instruction for general 
education courses such as "Introduction to Human Communication" (HCS100) and "Writing Intensive First Year Seminar" (WIFYS, ENG114).

Prior to 2016, the library did not employ a librarian dedicated to STEM departments, such as physics, computer science, and mathematics. While the faculty librarians did their best to serve these departments, the lack of a colleague who understood the unique library needs of STEM departments resulted in these departments adapting a do-it-yourself approach to information literacy instruction, thus decreasing their use of library services. In 2016 the library hired a STEM librarian to specifically foster connections with the underserved departments and to increase the presence of STEM resources and instruction within the library.

\section{Specific Case}

Engagement with the mathematics department began in August 2016, when the STEM librarian sent emails to each full-time and adjunct faculty member within the department describing library services available to instructors and their students. After no response from the department for the first two months of the semester, the STEM librarian attended a mathematics faculty meeting to advertise library services and specialized library instruction in person. This in-person pitch resulted in a single tenured faculty member seeking library instruction for two sessions of his "Fundamentals of Mathematics" class (MAT 110) in the fall of 2016.

The MAT 110 class is taught to education majors, typically in their first two years at Shippensburg University. In addition to refreshing students on algebra and geometry skills, the course teaches students how to present mathematic concepts in the classroom. In order to enhance their understanding of teaching methods for mathematics classrooms, the professor required students to complete two professional connections papers. These papers were to be a two to three page long 
summary and reflective analysis of a single article chosen by the student from a professional practitioner journal on a topic covered in the MAT 110 course. Students were required to correctly cite the article they chose for each of their papers.

The librarian met with the professor after receiving the description of the assignment to further discuss the specific needs of the class. In this meeting the mathematics professor and STEM librarian decided that the students would most benefit from bibliographic instruction combined with a demonstration of American Psychological Association (APA) citation basics. Prior to the instruction sessions, the librarian created a LibGuide for the class, which contained curated resources, such as journal searches and database lists, and citation assistance materials that the professor could link to from the course page on Brightspace (D2L), the learning management system.

Students in MAT 110 met in the library computer lab and began with a brief orientation to the library and the library website. Following this orientation, the class was taught how to navigate to the course LibGuide and was asked to participate and follow the library instructor's directions for the remainder of the session. The librarian modeled for the class how to conduct a database search using Education Source, ERIC, and Teacher Reference Center, and how to use filters within these databases following keyword generation. The class was then shown how to use the article preview to determine if an article met the requirements of their assignment, including how to tell if an article came from a professional practitioner journal, and was given a brief amount of time to practice searching the databases. The librarian then showed the class how to search the library journal collection for specific professional practitioner journal. The session concluded with a brief discussion of APA citation style, with the librarian showing students how to find and use the Purdue Online Writing Lab (OWL) website. 


\section{Outcomes}

After the bibliographic instruction session, two students scheduled appointments with the STEM librarian and another individual student reached out via email for assistance with the professional connections assignments. In all three cases, the students wanted citation assistance as well as a second opinion on whether or not a specific article counted as a professional practitioner article.

At the conclusion of the semester, the fundamentals of mathematics faculty member provided feedback via email and casual conversations indicating the quality of the articles selected by the students was an improvement from past semesters; however, the students' approach to citations was not quite what the mathematics faculty member had envisioned. Students were neglecting important elements within their citations or were inventing their own styles of citing the articles that were selected for their professional connections assignment. As such, an adjustment to the lesson plan was made and more time was spent reviewing how and why APA citation style should be used during the instruction session held with the fundamentals of mathematics course in the spring of 2017.

In the revised lesson plan, APA citations were introduced by first explaining the concept of a citation and its use. Students were told that citations give credit to the original thinkers and creators of a work and that proper citation ensures people who are interested in the work of the original thinker or creator can find it with ease. When the librarian felt the students understood the directional purpose of a citation following in-class feedback from the students, she then moved on to how to create a proper APA citation. The students were asked to follow along with the instruction by creating a citation using the process being demonstrated on one of the articles they found during the searching time they were given during class. The librarian first directed the students to the Purdue OWL website, where she 
showed them how to identify which type of citation they needed for the material they were citing. The librarian then pulled up an example journal article citation on the OWL website and broke down each part of a citation into where one would likely see that information in a journal article. Then, the STEM librarian demonstrated how to create a citation from scratch using all the information they found in their articles. To conclude, the librarian illustrated to the students how to export a citation from EBSCO databases and how to correct discrepancies in the citation exported and the proper APA format. Students were instructed to seek assistance from a librarian with citations if they felt unsure about what they were doing.

After the spring 2017 class five students reached out to the STEM librarian for assistance in ensuring their citations were accurate. This was an increase over the three students who reached out after the session offered during the fall semester. This may have been due to the increased emphasis on the importance of citations in the revised lesson. It also may have been due to the direction to seek assistance with citations when unsure about proper formatting; letting the students know this is something librarians are able to assist them with. After hearing feedback about the experience and the improvement in student work from the MAT 110 professor, a different mathematics faculty member has reached out to develop ways to include library instruction in his freshman seminar and upper-level research courses in the fall of 2017.

\section{Lessons Learned}

Information literacy instruction for mathematics needs to be adapted from standard outlines and practices to point a narrow lens at the skills and specific needs mathematics students will need. While mathematics students still need to seek and use information, the literature available on mathematics topics can be particularly onerous to evaluate. The language of mathematics can prove 
difficult to navigate, as mathematics literature is filled with jargon and discerning the subtle differences between mathematical concepts requires an understanding of both information seeking and mathematics. The seeking and evaluation processes require more time than does the conversation of how to effectively use information, though the discussion surrounding ethical use of information (such as the inclusion of proper citations) needs to be emphasized, because mathematics students use their citation skills less frequently, as paper-writing and citation-based assignments are less common to the field of mathematics.

Going forward it may be useful to assess the tools and strategies the mathematics faculty are currently using to teach information literacy to their students. A better understanding of their current practices may illuminate the areas of greatest need and inform the lesson planning process for bibliographic instruction sessions taught by the STEM librarian for the mathematics department. Through application of these principles, this assessment would further increase the visibility of the library and encourage more mathematics faculty to seek library instruction sessions and other specialized resources.

\section{References}

Awasom, I.A. (2017). Science librarian and faculty collaboration to enhance information literacy and critical thinking skills in undergraduate and graduate students in the STEM fields. Presentation, Georgia International Conference on Information Literacy, Savannah, GA, September 15-16, 2017.

Harris, S. Y. (2017). Undergraduates' assessment of science, technology, engineering and mathematics (STEM) information literacy instruction. IFLA Journal 43(2), 171-186. doi:

$10.1177 / 0340035216684522$ 
Hartman, P., Newhouse, R., \& Perry, V. (2014). Building a sustainable life science information literacy program using the train-the-trainer model. Issues in Science and Technology Librarianship, 77. doi:10.5062/F4G15XTM

Jing, W. (2017). Information literacy- Math 129 Precalculus Mathematics I Redesign (final report), Chesnutt Fellows Information Literacy Projects 2. Retrieved October 31, 2017 from: http://digitalcommons.uncfsu.edu/div_aa_library/2

Li, P. (2012). Math graduate students' information behavior and their need for information literacy instruction. Proceedings of the Annual Conference of CAIS. Retrieved October 30, 2017 from: https://journals.library.ualberta.ca/ojs.cais-acsi.ca/index.php/cais-asci/article/view/690

Scaramozzino, J. M. (2010). Integrating STEM information competencies into an undergraduate curriculum. Journal of Library Administration 50 (4), 315-333. doi:10.1080/01930821003666981

Shippensburg University. (2017). Fast facts about Shippensburg University. Retrieved October 23, 2017 from: http://www.ship.edu/About/Fast_Facts_About_Shippensburg_University/.

Stitz, T. (2010). Learning from personal experience what's needed in information literacy outreach: An engineering student returns to her alma mater as an engineering librarian," Science \& Technology Libraries 29 (3), 189-199.

Storksdieck, M. (2016). Critical information literacy as core skill for lifelong STEM learning in the $21^{\text {st }}$ century: Reflections on the desirability and feasibility for widespread science media education. Cultural Studies of Science Education 11 (1), 167-182. doi: 10.1007/s11422-015-9714-4.

U.S. News \& World Report. (2017). Shippensburg University of Pennsylvania. Best Colleges Rankings. Retrieved October 23, 2017 from: https://www.usnews.com/best-colleges/shippensburguniversity-3326. 